(6) Trichacis (Platygaster) remulus Walk. of 9 .

(7) Polygnotus (Platygaster) minutus Lind. $\delta$.

(8) Anaphes pratensis Först. ㅇ. (Egg parasite).

With these were also $\delta q$ specimens of Isosoma brevicorne Walker, which must be a gall-maker on the oats.

Most of the above parasites were bred from their host, occurring in oat stubble, collected in 1894-95, at Poitier and Montreuil. The rearing of Anaphes pratensis Förster, is most interesting, since it is without doubt an egg parasite.

Host. 3. Cecidomyia tritici Kirby.

( I) Merisus destructor Say $\delta$.

\title{
DIPTERA FROM THE WHITE SANDS, ON THE TULAROSA PLAINS OF SOUTHERN NEW MEXICO.- I.
}

By C. H. TYleR TOWNSEND, LAS CRUCES, N. MEXICO.

The Tularosa plains may be roughly described as lying between the Sacramento Mts. on the east, and the San Andres Mts. on the west, and stretching from the Organ Mts. north to the vicinity of White $\mathrm{Mt}$. They are some 80 miles long, by 30 or 40 wide.

In the northwestern extent of these plains there reposes a reınarkable and extensive surface deposit of disintegraded and weathered gypsum, covering an area some 35 or 40 miles long by an average width of ro miles, and varying in depth from a mere crust to ridges piled up $30 \mathrm{ft}$. above the level of the surrounding plain. This immense deposit is known as the White Sands. The gypsum is pure, without grit, and nearly white, and the banks of it appear from a little distance almost like banks of snow shining in the sun. From the road going up into the Sacramento Mts., in the Rio Tularosa cañon, a splendid view of this gypsum area is obtainable. A view is had at a point some I $200 \mathrm{ft}$. above the plain, and although the spectator is then distant at least 30 miles, the effect is striking in the extreme. The vast stretch of sands lies spread out upon the plain in a panorama of billows, and it is hard to resist the impression that one is looking upon a distant arm of the sea, where a high surf is rolling up upon the sandy beach. The San Andres range, lying close by the western edge of the Sands, enhances the effect, and appears like a rocky promontory washed by the waves. When one comes to walk over the Sands, he finds that the immense

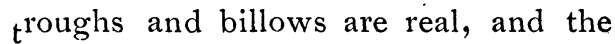
gypsum is seen to assume all the undulations and forms that the winds of the plains are capable of producing.

These Sands are scatteringly covered with a considerable vegetation through- 
out their whole extent, so far as I have examined them, and their insect fauna is considerable as may be inferred. The wagon road from Las Cruces or El Paso to the Sacramento Mts. skirts the edge of the Sands for some ro miles. Some few plants and insects collected along the edge, while passing them, have shown a very large percentage of new forms - new varieties among the plants, and new species among the insects. Such an extensive region, possessing such markedly peculiar characteristics, and unique conditions of environment, must truly have a flora and fauna of its own. The region promises great returns to the investigator of its flora and fauna. But water is extremely scarce in the vicinity, and the heat and glare are almost unbearable in the summer months, so much so that travellers always pass the Sands if possible at night. It therefore requires more than ordinary courage to attempt an investigation at this season. The best months to visit the locality are October and November. Many plants are then to be found in bloom on the Sands, and the heat while still very grèat is within the limits of endurance.

The present paper is the result of the determination of a small lot of diptera taken by the writer on the edge of the Sands at White Water Holes, and on the plain close by, during a couple of hours collecting on the afternoon of Oct. 6, I896. White Water Holes, which sometimes contain a brackish water but are often dry, are situated on the road within a few feet of the high banks which form the edge of the Sands. They are about 7 miles north from Lunas well (Pelman's ranch), and 40 miles from Tularosa.

All specimens with locality White Sands were taken a short distance over the sand hills from White Water Holes, and actually within the area of the Sands. All those with locality White Water Holes were taken on the plain a few yards from the edge of the sands. Not more than a half hour, in the late afternoon, was spent within the limits of the Sands, and the area covered was not more than 100 yards in diameter.

The reader is referred, for other notes on the White Sands, to the writer's second paper on the biogeography of Mexico and the Southwestern U. S. (Trans. Texas Acad. Sci., I897.)

I. Paragus bicolor Fab. var. testaceus Meig. Two $q \mathrm{~s}$, and three $\delta \mathrm{s}$, near edge of Sands, at White Water Holes, Oct. 6. On flowers of Aster parviflorus Gray. Length, 5 to 6 mm. All constant in the color of the abdomen. The black is confined to the first segment, and anterior corners of second. The males have the first segment wholly black, but both females have an elongate transverse marking of red on hind margin of first segment in middle. All have at least a brownish trace of the blackish annulus on hind tibiae.

Williston says that $P$. bicolor has a distinct vertical glabrous stripe on the eyes. It really has three such stripes, the other two being on anterior and 
posterior margins of eye, which are bare. The eyes are better described as having two very distinct parallel vertical stripes of pubescence, for the whole glabrous area of each eye is confluent.

I have already recorded this species from New Mexico, from the Mesilla Valley of the Rio Grande at Las Cruces (Trans. Am. Ent. Soc. Mch. I 895). The single female there mentioned, taken August 19, belongs also to the variety testaceus (as Snow later stated in Kans. Univ. Quart. April, 1895).

2. Paragus tibialis Fall. var. dimidiatus Lw. One $q$, and four Js. Near edge of sands, at White Water Holes, Oct. 6. On flowers of Aster parviflorus Gray. Length, $3 \frac{1}{2}$ to nearly $5 \mathrm{~mm}$. The vertical triangle of $\delta$ is about twice as long as greatest width. In the preceding specimens of $P$. bicolor var. testaceus, it is about three times as long as greatest width. I believe that the American forms are to be classed with the European varieties. But the European form with only the first two segments of abdomen black and tip with or without black, according to Schiner who paid particular attention to these varieties, possesses no distinctive name. At least Schiner gives none. Loew, however, described this form as dimidiatus, except that he included with it a $q$ of the typical form, which is distinguished by having no red on the abdomen. I think it will be permissable, therefore, to use Loew's name for this variety, with the abdomen red except first and second segments.

The above specimens are moderately constant. The $q$ has the first two segments completely greenish-black. The $\delta \mathrm{s}$ all have the hind border of second segment red, sometimes widely so, one $\delta$ having second segment only narrowly black on front border. The $q$ has tip of abdomen, being last half of fifth segments and all of rest, blackish. The $\delta \mathrm{s}$ have only a brownish tinge on last half of fourth, and anterior margin of fifth segments. Femora all black, except yellow tips.

This is the first record of this species from New Mexico. It is recorded from Colorado on the north, and Sonora on the south.

3. Zodion fulvifrons Say var. $a b$ dominale Say. One $\$$. Near edge of Sands, at White Water Holes, Oct. 6. On flowers of Aster parviflorus Gray. Length, $6 \mathrm{~mm}$. Front silvery along orbits, yellow, reddish-yellow at vertex. First two antennal joints and upper side of femora tinged with brownish. The third or median narrower brown vitta present. Second and sixth abdominal segments yellowish, with a median reddish line, rest brownish. All silvery pollinose, except median line of sixth segment. Pair of median stripes indistinct, but traceable on third and fourth segments. (See paper on Dipt. Organ Mts., for further notes on this variety.) 

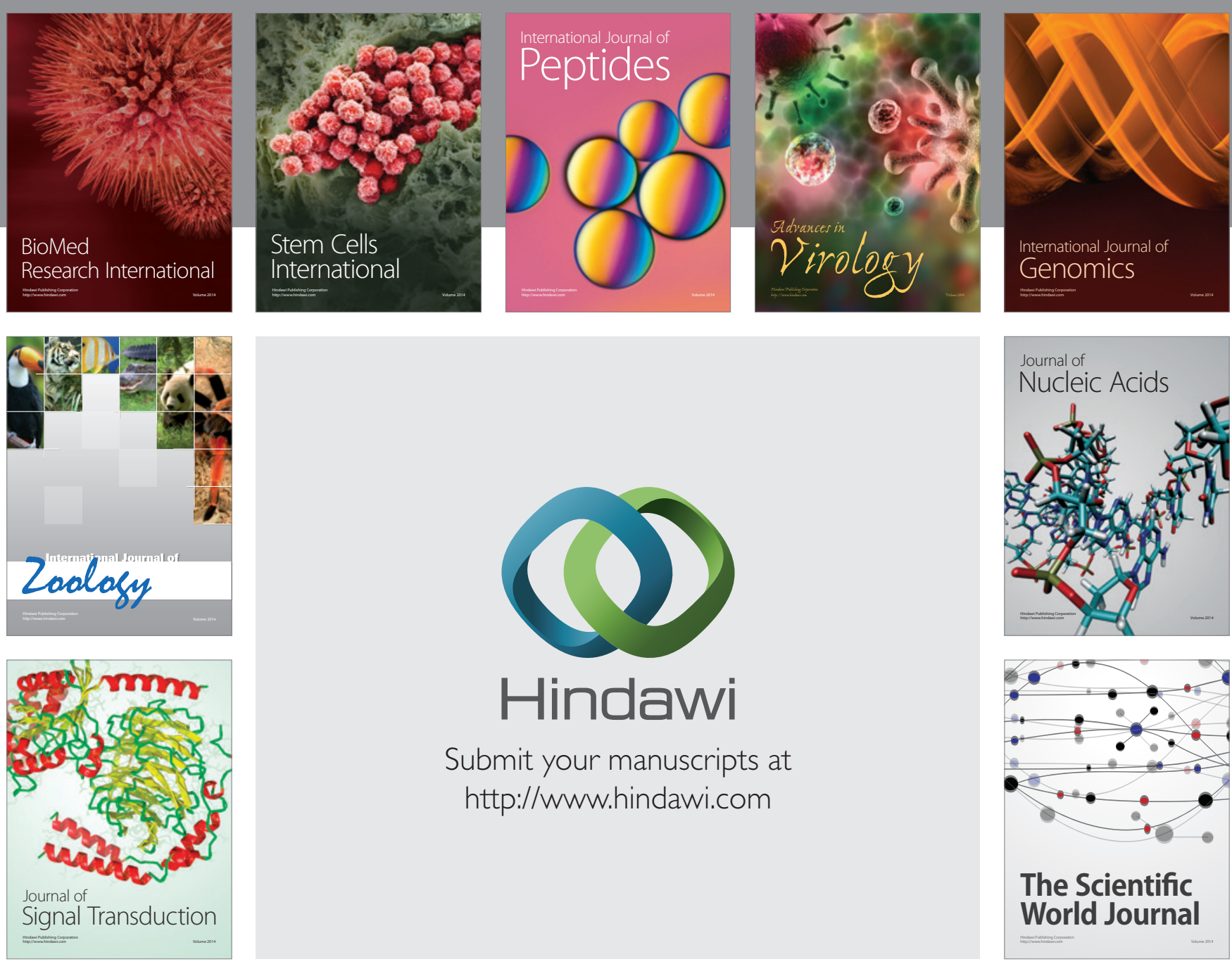

Submit your manuscripts at

http://www.hindawi.com
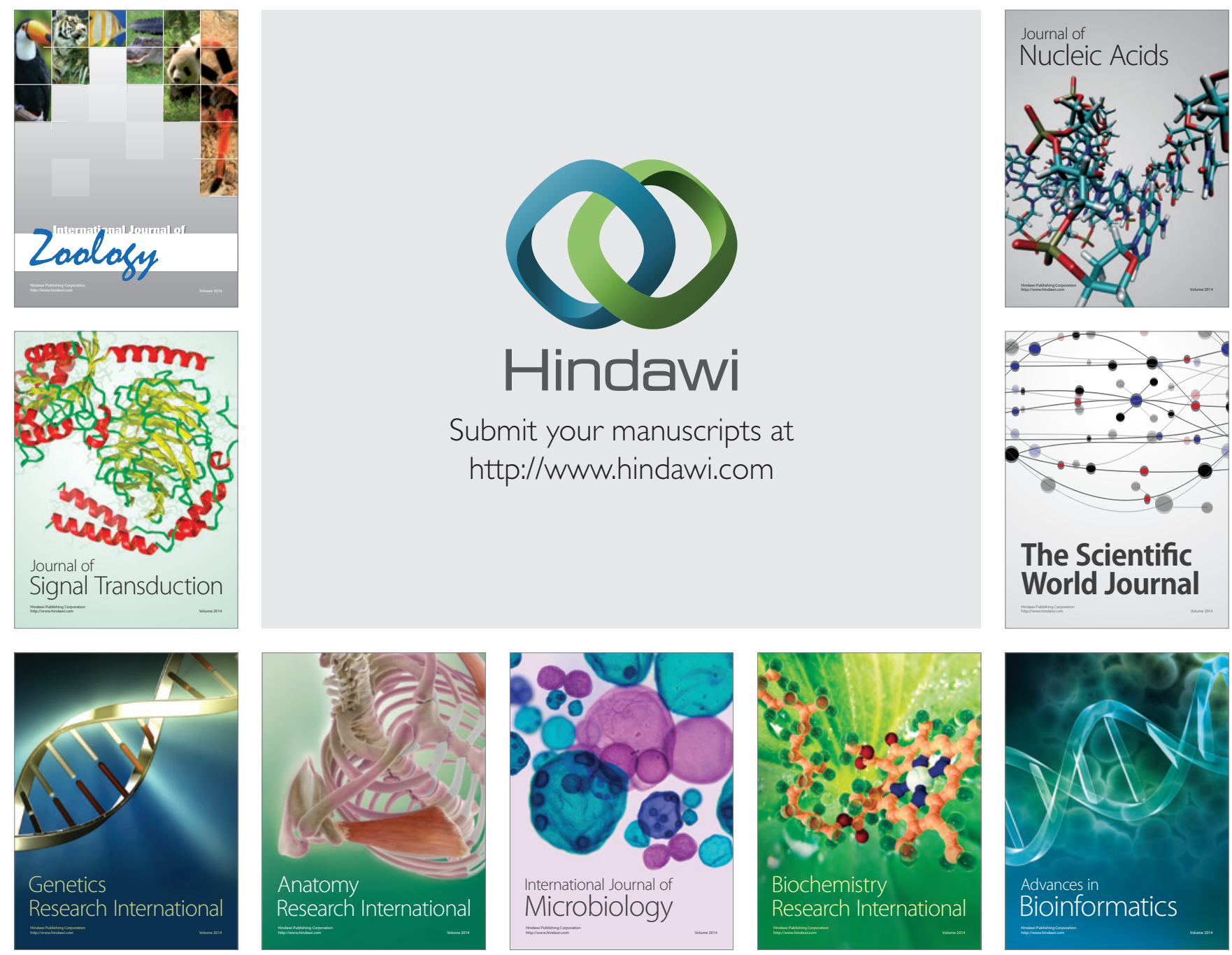

The Scientific World Journal
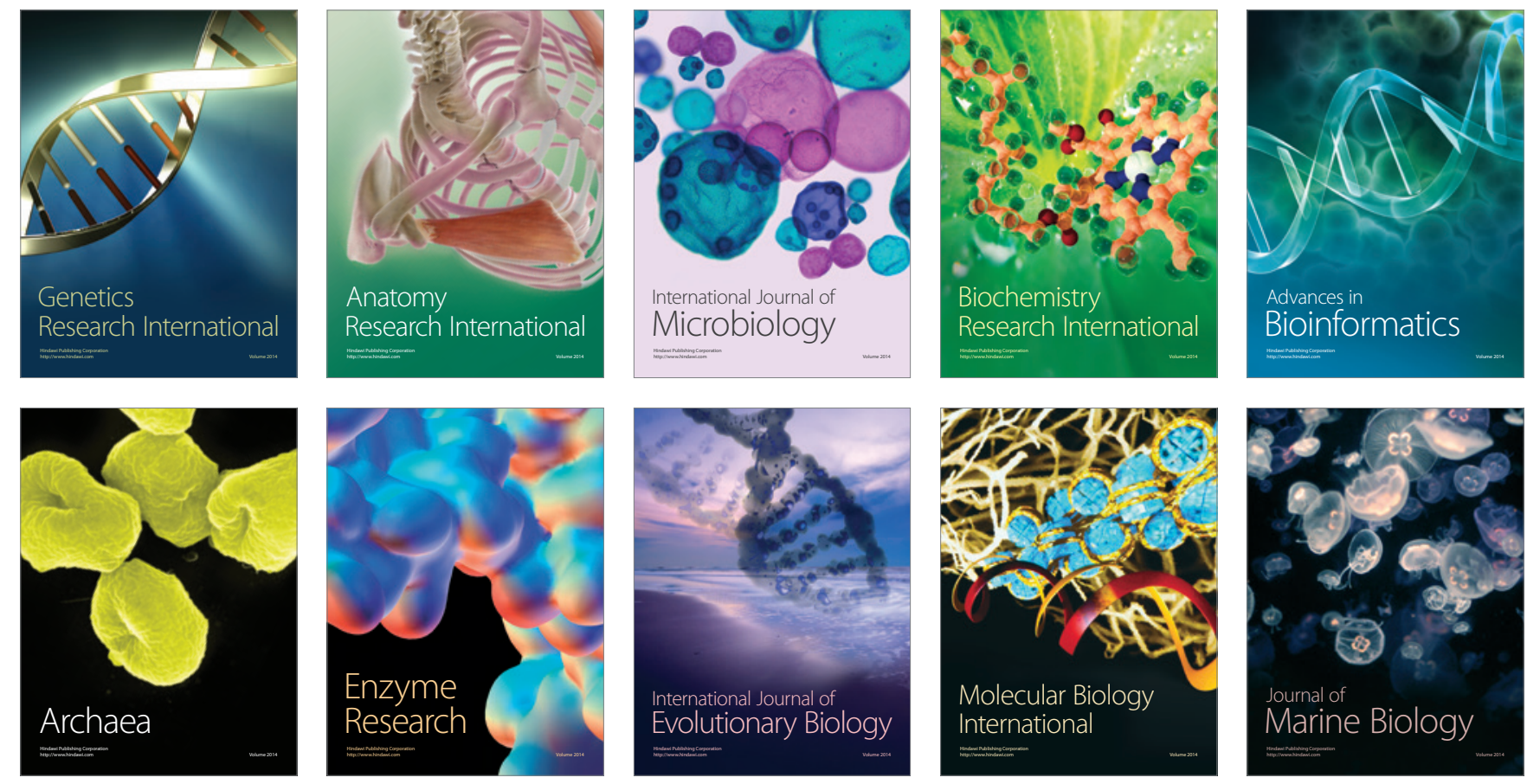